\title{
FIM DAS CLASSES SOCIAIS? O DEBATE CONTEMPORÂNEO NA EUROPA E NO BRASIL
}

Fabricio Barbosa Maciel*

\begin{abstract}
Resumo
Este artigo se divide em duas partes: na primeira, apresenta-se uma síntese sobre a discussão em torno do fim das classes sociais e de sua perda de relevância analítica no debate europeu contemporâneo, marcado principalmente pelo contexto histórico do fim do welfare state. Na segunda parte, faz-se uma análise sobre o debate acerca do surgimento de uma nova classe média no Brasil, o que, para alguns autores, significa uma nova classe trabalhadora. Como conclusão, apresenta-se uma breve análise sobre a diferença do tratamento do tema das classes sociais na Europa e no Brasil contemporâneos, o que reflete suas respectivas realidades empíricas.
\end{abstract}

Palavras-chave: Classes sociais. Welfare state. Individualismo. Nova classe média. Nova classe trabalhadora.

\footnotetext{
* Doutor em Ciências Sociais pela Universidade Federal de Juiz de Fora (UFJF), com estadia de sanduíche de um ano na Pädagogische Hochschule de Freiburg (PH Freiburg), Alemanha. Pós-doutorado em Sociologia na Universidade Humboldt, de Berlim, na Alemanha. Atualmente, é professor adjunto do Departamento de Ciências Sociais no Instituto de Ciências da Sociedade e Desenvolvimento Regional da Universidade Federal Fluminense (UFF). E-mail: macielfabricio@gmail.com.
} 


\section{Introdução}

A ideia de que vivemos o fim das sociedades de classe é um dos principais paradigmas dominantes hoje nas ciências sociais, complementando-se com a teoria do fim da sociedade do trabalho. As duas perspectivas, no fundo, compõem um mesmo pensamento, originado da teoria social pós-welfare state europeia. Durante o welfare state europeu, as ideias de sociedade industrial, de classes e do trabalho eram sinônimas. Com o advento do domínio de conceitos como globalização, nova ordem mundial e nova ordem multipolar, a importância teórica e política dos conceitos de trabalho e de classe se tornou residual para grande parte da ciência social dominante.

Diante do atestado de óbito teórico e político da classe e do trabalho, vindo principalmente da Europa, novas perspectivas se apresentam como candidatas a novos paradigmas dominantes. No caso do paradigma do trabalho, a teoria da sociedade do conhecimento (GORZ, 2004) se apresenta como uma de suas principais substitutas, ainda que cheia de falhas. No que diz respeito ao paradigma das classes sociais, existe também uma importante literatura, hoje já dominante, que se posiciona explicitamente como um paradigma alternativo.

Partindo disso, este artigo se divide em duas partes: na primeira, apresenta-se uma síntese sobre a discussão em torno do fim das classes sociais e de sua perda de relevância analítica no debate europeu contemporâneo, marcado principalmente pelo contexto histórico do fim do welfare state, que faz nações tradicionalmente estabelecidas no capitalismo, como França, Inglaterra e Alemanha, presenciarem uma precarização do trabalho e uma instabilidade social sem precedentes; na segunda parte, faz-se uma análise sobre o debate acerca do surgimento de uma suposta nova classe média no Brasil, o que, para alguns autores, significa uma nova classe trabalhadora, como veremos. A metodologia adotada para tal tarefa consistiu na revisão de literatura especializada, tanto europeia quanto brasileira, sobre o suposto fim das classes sociais nas 
sociedades contemporâneas. Como conclusão, apresenta-se uma breve análise sobre a diferença do tratamento do tema das classes sociais na Europa e no Brasil contemporâneo, o que reflete suas respectivas realidades empíricas.

\section{O desaparecimento das classes no pensamento europeu atual}

Ulrich Beck (1986, 1997, 2007) é um dos autores que apresenta uma tentativa de definição do novo mundo pósbipolar, globalizado e pós-industrial, no qual as classes sociais não teriam mais um papel político e analítico central. Antes da publicação de seu livro Sociedade de risco (no original, Risikogesellschaft), de 1986, o autor já lançara várias teses sobre o trabalho e as classes que, depois, se disseminaram na obra de vários autores. André Gorz (2004), por exemplo, compartilha da tese do fim da sociedade de classes, porém, o autor o faz indiretamente, pois a pedra de toque de toda sua obra é o advento do conhecimento como força produtiva em lugar do trabalho.

Curiosamente, Beck (1986) não abandona a ideia de trabalho e tenta resgatá-la, mas abandona a ideia de uma sociedade de classes. Em um dos capítulos mais famosos de seu livro Sociedade de risco, chamado Jenseits von Klasse und Schicht (Para além de classe e camada), ele lança uma de suas teses mais famosas, a de substituição do significado teórico e político da classe pelo de individualismo, fazendo-o através de uma análise de como as mudanças sociais do trabalho fragmentam a família. A tese é ambígua, o que explica seu forte poder de influência. $\mathrm{O}$ autor defende também que a desregulação do trabalho e o advento crescente das mulheres no mercado fragmentam casamentos e conduzem ao que Richard Sennett mais tarde definiu como “corrosão do caráter" (SENNETT, 2006).

A tematização do individualismo é ambígua. Robert Castel (1998) também relaciona um "individualismo negativo" 
com a fragmentação das condições de trabalho. Porém, Beck propõe o individualismo como um novo paradigma em substituição ao paradigma da classe (BECK, 1986, 1997, 2007), o que é bem diferente. Para ele, a desigualdade social da sociedade do risco - ou da segunda modernidade, como ele nomeia - opera muito mais entre indivíduos do que entre classes, ideia que ele continua desenvolvendo e aperfeiçoando até hoje. Essa tese é ambígua e, por isso, deve ser enfrentada, pois não nega a hierarquia social e sugere uma radicalização da meritocracia, com o que concorda Castel (2011).

Um lado positivo da tese do individualismo é que, com ela, compreendemos que vivemos em um mundo de competição mais acirrada entre indivíduos, conformados pelos novos critérios morais e normativos do trabalho. Tratase de uma atualização do individualismo, tese já presente na obra de Max Weber (2004), quando este percebeu que o desencantamento do mundo significa o fim dos laços de comunidade e de solidariedade, tendo agora cada indivíduo a própria responsabilidade sobre seu destino, o que, no mundo moderno, significa a obrigação moral e intersubjetiva de ser condutor da própria trajetória. Traduzindo para a linguagem contemporânea da meritocracia, isso significa que cada pessoa é responsável por sua própria carreira, sendo o fracasso imperdoável (SENNETT, 2007).

Na teoria social brasileira, Jessé Souza (2003) permite ver que o individualismo negativo, nesse aspecto, é desde sempre a realidade de nossa "ralé", como ele define, cuja marca principal é exatamente a da família desestruturada, dentre outros motivos, pelo desemprego estrutural. Assim, a percepção crítica sobre o individualismo pode ser complementar a uma teoria de classes e não necessariamente se tornar a sua negação. A realidade empírica das classes sociais em países da periferia do capitalismo permite essa associação. Por outro lado, com o aumento sem precedentes do trabalho precário e indigno na França, Robert Castel (2008) percebe a relação entre "desfiliação social" e individualismo. A desfiliação social significa, para este importante autor, a expulsão do mercado 
sem possibilidade de volta ou mesmo a não inserção de um número crescente de pessoas, o que resulta em afrouxamento e em perda de laços sociais na vida pessoal.

O lado negativo da tese do individualismo é que seu conteúdo se transforma facilmente em substituto do paradigma da classe e do trabalho. Podemos considerar, por exemplo, o caso da nova classe trabalhadora brasileira (SOUZA, 2010): são trajetórias individuais que encontramos quando vemos a ascensão de milhões de brasileiros, em grande parte oriundos da "ralé", filiando-se ao mercado através de um saber popular e de uma economia popular, informal, em sua maioria, mas não necessariamente precária. Isso não significa o fim das classes sociais. Pelo contrário: quando esses indivíduos mudam de condição social, eles se transformam em uma nova classe, pois apresentam trajetórias individuais semelhantes.

Robert Castel não tem uma teoria sobre as classes sociais, mas tem uma tese sobre o individualismo negativo e sobre as mudanças sociais do trabalho que o condicionam. É uma lacuna em seu lado historiador, preocupado exaustivamente com a mudança da questão social desde a sociedade pré-salarial até a sociedade pós-salarial. Já Ulrich Beck, por outro lado, é um consistente opositor da classe - um inimigo distinto, pois não a nega, apenas a admite como residual e como categoria analítica descritiva, um conceito "zumbi" diante da força maior do conceito de individualismo (BECK, 1986). No fim das contas, dizer que a classe é uma categoria residual significa retirar toda a sua força analítica e política.

Pierre Bourdieu pode ser o principal autor para a recuperação de uma teoria de classes e para seu desenvolvimento a partir dos imperativos de uma sociedade do trabalho e de classes renovada, se quisermos manter a validade histórica desses conceitos. Com o conceito de babitus, em seu livro $A$ Distinção, Bourdieu (2007) identificou traços comuns que assemelham as pessoas simbolicamente e as aproximam na prática, definindo padrões e barreiras de classe. Ele foi decisivo, por exemplo, na pesquisa sobre a "ralé" brasileira (SOUZA, 2009), em sua condição de estática social, totalmente não 
filiada ao mercado produtivo e não portadora da condição de consumidor, contrária à do indivíduo considerado digno em uma sociedade meritocrática.

Bernard Lahire (2006), por outro lado, apresenta a contribuição da teoria das disposições, que tematiza mais o indivíduo do que a classe, sem negar a última, porém contribuindo em boa parte para o pensamento dominante de seu tempo, o do fim da sociedade de classes. Com as ideias de "disposições individuais"e de "contextos de atualização" de tais disposições, é possível precisar o conceito de habitus de classe (LAHIRE, 2006). Ao invés de comprovar uma sociedade de indivíduos, como no fundo faz Lahire, que também transforma a classe em algo residual, em contraposição a seu mestre, Bourdieu, pode-se também perceber o contrário: as mudanças nas trajetórias individuais significam mudanças na conformação de classes de uma sociedade, pois se adquire um novo status social e um perfil que não é individual, mas semelhante às histórias de vida de inúmeras outras pessoas. Trata-se, portanto, da formação de uma classe social.

A teoria dos capitais de Bourdieu (2007) talvez nos ajude a enxergar a classe muito mais no caso das classes médias e dominantes do que no caso das classes populares, definidas mais pela ausência do que pela posse de capitais. Para o autor, as classes dominantes são portadoras principalmente (mas não só) do capital econômico, o que significa patrimônio acumulado por famílias, herança, e investimentos. As classes médias possuem principalmente capital cultural, estabelecidas sobretudo nas profissões liberais.

Três outras perspectivas teóricas contemporâneas nos ajudam a perceber a existência de classes sociais no atual mundo globalizado. Elas fazem parte do pensamento dominante no Atlântico Norte, que, direta ou indiretamente, não conseguem esconder a existência de classes sociais na nova realidade mundial de radicalização e de institucionalização da precariedade, do individualismo e da meritocracia.

A primeira delas considera o advento contemporâneo de uma nova elite global. Vários dos autores mais influentes 
no Atlântico Norte já perceberam a existência de uma classe dominante transnacional, pequena em número (ela se resume a um numero relativamente pequeno de famílias e de empresas), mas portadora da maioria das ações do capital financeiro internacional. Isso é nada mais nada menos do que uma classe social - mais especificamente, uma classe dominante transnacional. Nos Estados Unidos, Peter Berger e Samuel Huntington (2004) organizaram uma pesquisa mundial de grande porte e financiamento, cujo resultado é o livro Muitas globalizaçôes: diversidade cultural no mundo contemporâneo (BERGER; HUNTINGTON, 2004). O próprio título já sugere o teor relativista do tema, que não percebe uma sociedade mundial articulada, mas sim casos culturais da globalização. O ponto importante é que, nesse livro, um dos traços gerais foi exatamente perceber a elite global.

Também Beck tematizou a elite global em dois de seus conhecidos livros: Was ist Globalisierung? (2007) e Scböne neue Arbeitswelt (1997). Para ele, essa elite é um conjunto de atores transnacionais que subjuga qualquer poder político nacional, tendo as agências internacionais do capital financeiro sob seu domínio. Ao seu lado, por ela financiada, encontra-se um estamento científico-tecnológico que auxilia o capital financeiro em sua atual configuração global. Richard Münch também estudou a elite global em recente livro intitulado Globale Eliten, lokale Autoritäten (MÜNCH, 2008). Críticos ou não, tais autores estão nos mostrando a existência e a ação incisiva para a reprodução da desigualdade mundial por parte de uma nova classe dominante transnacional.

A segunda perspectiva advém da teoria das redes transnacionais. Manuel Castells (2010) é conhecido por sua teoria da sociedade da informação e da sociedade de redes. Ele também percebe a elite global, mas com um acréscimo importante: as redes transnacionais são redes impessoais que interligam a elite global e o estamento científico-tecnológico. Porém, elas também podem ser redes pessoais, ou seja, trata-se também do capital social dos ricos, que é fundamental para o compartilhamento de informações raras em tempo real como, 
por exemplo, onde investir e como agir na bolsa de valores. Trata-se, assim, de uma rede social internacional que mantém boa parte do capital financeiro circulando em poucas mãos.

A terceira perspectiva pode ser vista na teoria dos milieus sociais. De autoria principalmente de Michael Vester (1993), ela parte do esquema vertical de classes de Bourdieu (2007), que definiu, em seu tempo, na França, as classes como dominantes, médias e populares. Vester procura, com a ideia de milieus (ambientes ou meios sociais), renovar uma teoria de classes diante das mudanças vividas, na Alemanha, nos anos 1970 e 1980, sendo muitas delas as mudanças sociais do trabalho. Os autores apontam, em espaços do "mundo da vida", identificados a partir de gostos culturais (como a música), o que pode ser considerado frações de classe, mostrando, assim, que as classes sociais são internamente heterogêneas, não sendo apenas definidas pelo status econômico e a posição em camadas sociais.

A tese de Vester é inovadora e também curiosa e ambígua, pois ela não deixa de mostrar que existem classes sociais, ainda que em uma sociedade do trabalho modificada. Entretanto, no fim das contas, ele atribui, para a compreensão da mudança social, peso maior aos milieus sociais do que às próprias classes em si mesmas. Trata-se, então, de uma versão sofisticada do pensamento dominante de seu tempo. Em sua construção, ele também enfrenta a tese do individualismo (assim como Ulrich Beck e Robert Castel, como referido anteriormente), uma das dominantes na Europa, e tenta articulá-la à formação de novos milieus sociais, fundamentais para a compreensão de uma sociedade de classes modificada. Sua compreensão de como as classes sociais se renovam contribui para entendermos a mudança social através da mudança na estrutura de classes. Com um esquema horizontal, construído a partir de Bourdieu, Vester nos mostra como posições políticas e origens sociais diferentes podem compor uma mesma classe social. Cabe dizer que a Alemanha não vive a ascensão de uma nova classe trabalhadora, como no Brasil.

O ponto mais importante é que ele contribui para que entendamos o novo conflito de classes contemporâneo, talvez 
o mais importante, e que ocorre talvez de forma mais radical na periferia, onde surge agora uma nova classe trabalhadora. Apesar disso, esse conflito está no "meio" da sociedade, não se limitando mais a suas "extremidades", pois se trata de uma nova luta de classes, agora entre as classes média e trabalhadora. Para Vester (1993), a Alemanha ainda é uma sociedade de classes, porém agora hierarquizada e verticalizada de outra maneira, uma vez que a maioria da população se encontra "no meio" da sociedade. Isso significa que ainda existe desigualdade de classe, porém de outra natureza.

A tese dos milieus sociais também nos ajuda a compreendero processo contemporâneo de transnacionalização das classes. A reprodução da elite global e da classe média tradicional cosmopolita e transnacional se opera através de redes de capital social que encontram suporte dentro dos milieus sociais destas classes. Naturalmente, o acesso ao capital social altamente valorizado dentro de milieus sociais restritos pressupõe a posse de elevado capital econômico e cultural, conforme Bourdieu (2007).

O pensamento de Vester (1993), bem como o de Lahire (2006), na França, reproduz discretamente o pensamento dominante europeu. Eles não puderam fugir da dominação da tese do individualismo. Trata-se, no fundo, ainda que com eles aprendamos, da reprodução discreta do senso comum científico sobre o fim das classes sociais e o fim da sociedade do trabalho, que domina o pensamento europeu pós-welfare state. Neste, os conflitos sociais são amenizados, como bem perceberam Boltanski e Chiapello (2005), que, ainda que tentem pensar as mudanças sociais do trabalho, centram sua tese na flexibilidade como imperativo inevitável e na perda de capacidade de crítica contemporânea ao capitalismo.

O que está em jogo no pensamento pós-welfare, explícita ou implícita, é a tentativa de substituição da tradição da sociologia do trabalho, que dominou a era definida como sociedade industrial: trata-se de uma tradição originalmente marxista, fundada na Escola de Frankfurt e em muitos outros locais. Esse é um dos principais aspectos de nosso "espírito 
da época" ditado pela ciência social dominante do Atlântico Norte. Gorz (2005), nesse contexto, apresenta uma das melhores tentativas de renovação da teoria do valor, mas, infelizmente, termina em uma "ontologia do imaterial", em lugar da "ontologia do capital" marxista.

Outro exemplo do pensamento dominante europeu vem de outro influente sociólogo alemão, Klaus Eder. Enquanto o fim do trabalho e da classe é explícito na obra de autores como André Gorz (2005) e Claus Offe (1994), em Eder ela é implícita e sofisticada. O pensamento quase profético de Offe (1994) de que o "mundo da vida" deveria ser estudado agora, em lugar do "mundo da produção", é aprimorado na principal obra de Eder, seu livro A nova politica de classes (EDER, 2002). Mais uma vez, a classe não desaparece da teoria, mas assume uma outra interpretação e outro significado, no qual o conflito é abandonado. A nova política de classes de Eder trata exatamente do que Claus Offe gostaria de ver: ele defende que os movimentos sociais de classe média, como aqueles em prol de questões ambientais, são a ação política mais importante, pois permitem ver alguma existência de classe no capitalismo contemporâneo.

Tais movimentos sociais de classe média, ainda que sustentem bandeiras importantes, parecem sobretudo uma busca por "autenticidade", ou seja, uma busca por identidade e por realização pessoal por parte de quem já tem "dignidade" (TAYLOR, 1997), isto é, quem está livre do risco de não ter o suprimento de suas necessidades materiais básicas. Essa teoria, entretanto, não pode negar a existência das classes sociais. A transnacionalização do movimento ambiental, por exemplo, é uma prova empírica inegável da existência de uma classe média internacional e cosmopolita, bem como de seus respectivos "milieus" transnacionais. Da mesma forma como, em Vester (1993) os milieus sutilmente tomam o lugar do peso analítico da classe, em Eder, os movimentos sociais realizam a mesma função e reproduzem implicitamente o pensamento dominante no contexto do fim do welfare state.

Por fim, cabe lembrar que, desde a tradição marxista, que dominou a interpretação da sociedade industrial, em suas 
várias vertentes, houve sempre a crítica sobre uma lacuna em relação aos estudos sobre as classes médias - afinal, Marx via a luta de classes exclusivamente entre o burguês e o proletariado, como bem sabemos. O pensamento dominante europeu procurou incluir as classes médias no debate, o que é um avanço inegável; por outro lado, ele parece ter perdido o interesse pelo conflito, o que se torna um grave problema para qualquer teoria social que pretenda ser crítica. Dessa forma, no geral, o que se presencia, em grande parte do debate contemporâneo dominante na Europa acerca das classes sociais, na sociedade atual, é que estas se tornam relativizadas, diminuídas, relegadas a um segundo plano analítico ou simplesmente negadas em sua existência empírica.

Vejamos agora como o debate brasileiro tem enfrentado a questão da classe social em sua realidade contemporânea e em que medida essa tematização se aproxima ou distancia do debate europeu. A comparação das duas realidades, a partir da literatura visitada, será fundamental para compreendermos a pertinência política do tema das classes no Brasil de hoje.

\section{O debate sobre as classes no Brasil contemporâneo}

Um dos principais debates, no Brasil e no mundo contemporâneo, seja na esfera pública, na grande mídia ou na academia, é sobre uma suposta nova classe média. Mangabeira Unger (2008) é um dos autores que ressaltam sua importância teórica e política no Brasil. Definida por ele como "segunda classe média", vinda de baixo, morena e originada da "ralé" (SOUZA, 2009), essa nova classe seria o principal motor do desenvolvimento das sociedades emergentes, tanto como novos agentes produtores quanto como novo e crescente público-alvo de consumo. Estas são as duas dimensões que articulam os indivíduos em uma sociedade meritocrática ou, como diria Castel (1998), que filiam os indivíduos ao mercado, conferindo-os dignidade. Paralelamente, encontramos uma discussão marxista, como a realizada na conhecida obra de Ricardo Antunes, especialmente em sua análise da "classe que 
vive do trabalho" (ANTUNES, 2000). O advento dessa nova classe trabalhadora pode ser visto tanto na mídia quanto em literatura especializada que trata de países como Indonésia, Turquia e, principalmente, China, Índia e Brasil - estes três últimos já considerados por muitos como economias que perturbam a dominação histórica das nações do Atlântico Norte.

Duas definições dominantes, pelo menos no Brasil, sobre a nova classe, são os conceitos de "classe C" e de "nova classe média”. O primeiro domina pesquisas empíricas que definem os emergentes, principalmente pelo critério da renda, mas também pelo critério do consumo, ambas as hipóteses comprovadas por pesquisas empíricas recentes, como as apresentadas em um dos últimos livros organizados por Marcelo Neri (2012). O conceito de nova classe média, por outro lado, procura ir além da função da renda e do consumo, procurando considerar também o estilo de vida e o gosto dos emergentes, notáveis principalmente em seu consumo, seu comportamento político e sua atitude no espaço público. Uma pesquisa nessa direção foi organizada pelos cientistas políticos Bolivar Lamounier e Amaury Souza, cujo resultado é o livro A classe média brasileira: ambiçôes, valores e projetos de sociedade (2009). A pesquisa dos autores, por se pautar mais a partir de um continuum entre a nova classe e a classe média tradicional, analisando a primeira do ponto de vista da última, acabou não percebendo a especificidade da nova classe (SOUZA, 2010). Em contrapartida, a pesquisa sobre a suposta nova classe média organizada, logo em seguida, por Jessé Souza apontou para outra direção. A partir da ideia de que o Brasil presencia hoje a ascensão imprevisível do contingente de uma nova classe de "batalhadores" (termo este que vem do próprio senso comum brasileiro), Souza (2010) procurou enfrentar, com referências teóricas alternativas, bem como com um método de pesquisa alternativo, os conceitos dominantes sobre o novo fenômeno, perspectiva que pode nos ajudar a enxergar algumas dificuldades e limites dos dois conceitos dominantes sobre o tema. Márcio Pochmann (2012) também abordou a questão 
como se tratando de uma "classe trabalhadora", porém, adotou uma perspectiva marxista, diferentemente de Souza (2010), que adota uma direção sócio-cultural.

Qual é o limite do conceito de classe C? A pesquisa nacional sobre os batalhadores brasileiros (SOUZA, 2010) mostrou que a renda, aspecto central do conceito de classe C, é um dos critérios menos importantes na definição de uma classe social, pois não serve à recuperação de sua gênese e de sua dinâmica. A principal referência teórica para tanto foi a articulação do conceito de habitus, de Bourdieu (2007), ao de disposições, de seu crítico Bernard Lahire (2006). $\mathrm{O}$ conceito de habitus procura tematizar as possibilidades de ação incorporadas pelos indivíduos desde a infância e situadas em sua educação formal e informal, escolar e familiar. O conceito de disposições aperfeiçoa o anterior, exatamente por criticá-lo: defende-se que o babitus, na obra de Bourdieu, muitas vezes parece sugerir mais estática do que dinâmica social e individual. Lahire (2006), em contrapartida e em complemento a isso, enfatiza que o babitus é mutável, e faz isso empiricamente, observando como indivíduos de habitus semelhantes, como dois irmãos de uma mesma família pobre, podem ter destinos diferentes. Por exemplo, um deles pode permanecer socialmente estático, desfiliado e desqualificado, enquanto o outro pode estudar e melhorar de vida, alcançando mobilidade social. As causas dessa diferença são enfrentadas pelo autor com o conceito de "contextos de atualização de disposições” (LAHIRE, 2006). Em termos simples, defendese que os contextos da vida individual podem permitir a pessoas de mesma origem o desenvolvimento de habilidades e destinos diferentes. Isso torna a análise muito mais dinâmica do que estática, bem como o é a realidade social.

Partindo dessa perspectiva e com um método de entrevistas em profundidade, que permite adentrar nas histórias de vida dos entrevistados, a suposta nova classe foi pesquisada nacionalmente, de forma que foram identificados alguns perfis considerados pelo pensamento dominante como nova classe "média" (SOUZA, 2010). Dentre eles, estão 
profissionais do telemarketing, feirantes, pequenos produtores rurais e pequenos comerciantes. Estas pessoas são exatamente o oposto de uma classe média "tradicional", pois não possuem herança ou patrimônio acumulado, não se ocupam de profissões liberais bem remuneradas e estabelecidas pelo Estado e pelo mercado e não possuem certificados escolares formais socialmente valorizados.

Sendo assim, podemos nos questionar sobre as dificuldades do conceito de nova classe média, aparentemente mais sofisticado do que o de classe C. O principal critério referente à classe média tradicional e que serve para definir a nova classe também como média é a capacidade de consumo. Essa perspectiva apresenta uma forte afinidade eletiva com um discurso político conservador, originado no Atlântico Norte, que considera países desenvolvidos apenas aqueles que possuem uma robusta classe média (SOUZA, 2010). Ao pesquisar com método de observação participante e entrevistas de profundidade a realidade cotidiana dos referidos perfis, os "batalhadores brasileiros" (SOUZA, 2010), público-alvo tanto do Estado quanto do mercado, mostrou-se que sua dinâmica social e sua condição histórica inédita exigem outros referenciais políticos e teóricos. Um dado fundamental nessa direção é o fato de que a nova classe trabalha em média 14 horas por dia (SOUZA, 2010), pois seus integrantes geralmente são autônomos sem vínculo formal que, por esforço próprio, sobrevivem na "zona de vulnerabilidade" (CASTEL, 2011) do capitalismo contemporâneo. Sem qualificação formal ou com muito pouca, eles levam um estilo de vida simples e sobrevivem através de um saber popular, alternativo ao "Conhecimento" conferido e reconhecido pela chancela oficial dos certificados e dos diplomas do sistema escolar e universitário, reconhecidos pelo Estado e pelo mercado. Por esses motivos, podemos perceber uma diferença fundamental entre a classe média tradicional e a nova classe trabalhadora: estes parecem muito mais uma nova classe trabalhadora, sendo ao mesmo tempo efeito e atores dos novos critérios de reprodução social de uma sociedade do trabalho reestruturada em sua dimensão global. 
Desta forma, enquanto boa parte do pensamento

europeu dominante contemporâneo está mais preocupada em substituir os paradigmas do trabalho e das classes sociais por paradigmas do mundo da vida, como o individualismo, os milieus e os movimentos sociais, vemos hoje, no Brasil, outras perspectivas teóricas e empíricas, que apontam para outra direção, não reproduzindo o paradigma dominante da negação das classes. $O$ fato empírico do surgimento de uma nova classe trabalhadora exige, agora, no pensamento brasileiro, uma tematização do fenômeno que, independentemente da orientação teórica assumida, não pode se furtar do fato evidente da existência de uma nova sociedade de classes reestruturada e mais complexa.

\section{Considerações finais}

A condição empírica da nova classe trabalhadora, bem como o seu significado político, permite-nos considerar a hipótese sobre a existência de uma importante mudança histórica no capitalismo contemporâneo, que Robert Castel (2011) chegou a considerar como a "segunda grande transformação" do capitalismo. Segundo ele, esta segunda transformação seria ainda mais profunda e complexa do que a primeira, analisada pelo clássico trabalho de Karl Polanyi, quando este percebeu o domínio do mercado auto-regulado como marco definidor do início das sociedades industriais (POLANYI apud CASTEL, 2011). Entretanto, na prática, durante todo o século XX - caracterizado pela sociedade industrial e salarial -, o mercado nunca foi de fato autoregulado, mas teve sempre os Estados nacionais como seus agentes ou reguladores. Agora, de acordo com Castel (2011), o mercado auto-regulado parece existir cada vez mais sem restrições.

Para Castel (2011) e para Beck (2007), um dos principais efeitos deste novo contexto é a institucionalização da precariedade e do individualismo. Para Jessé Souza (2010), a partir da pesquisa sobre os "batalhadores brasileiros", tem-se 
uma nova dominação do capital financeiro, cujos efeitos no

1 Nesta direção, ver também Maciel (2014).
Brasil são discutidos pelo autor. ${ }^{1}$ Beck (2007) considera tais efeitos oriundos do processo de globalização, no qual as forças e os agentes financeiros transnacionais sucumbem os Estados nacionais e radicalizam desigualdades de toda espécie. Todos os autores europeus aqui analisados concordam que a gênese da precariedade pode ser identificada no fim do welfare state. No Brasil, Jessé Souza (2003) mostrou que a precariedade é nossa velha marca estrutural, ainda que agora ocorra uma melhora relativa na vida de parte das classes populares.

Como conclusão, percebemos que o debate sobre as classes sociais, na Europa, hoje, aponta para o contexto do fim do welfare state e a consequente institucionalização do individualismo, bem como o crescimento da precariedade das condições e das relações de trabalho, o que autorizou vários de seus autores mais influentes a declararem o fim das classes sociais de forma indevida. Por outro lado, em países emergentes, como o Brasil, observa-se hoje um processo crescente de mudança social, presenciando-se o surgimento e o fortalecimento de uma nova classe trabalhadora no contexto pós-fordista do capitalismo financeiro, o que nos permite defender a necessidade de uma teorização renovada sobre as classes sociais, ao invés de sua negação. Os dois contextos teóricos e empíricos, se articulados, podem fornecer boas pistas para uma teoria crítica renovada do capitalismo contemporâneo em sua totalidade.

\section{Referências}

ANTUNES, Ricardo. Adeus ao trabalho? Ensaio sobre as metamorfoses e a centralidade do mundo do trabalho. São Paulo: Cortez, 2000.

BECK, Ulrich. Risikogesellschaft: Auf dem Weg in eine andere Moderne. Frankfurt am Main: Suhrkamp, 1986.

2007.

. Schöne neue Arbeitswelt. Frankfurt am Main: Suhrkamp,

. Was ist Globalisierung? Frankfurt am Main: Suhrkamp, 1997. 
BERGER, Peter; HUNTINGTON, Samuel.Muitas globalizações:

diversidade cultural no mundo contemporâneo. Rio de Janeiro:

Record, 2004.

BOLTANSKI, Luc; CHIAPELLO, Eve. The new spirit of capitalism. 2. ed. New York: Verso, 2005.

BOURDIEU, Pierre. A distinção: crítica social do julgamento. São Paulo: Edusp; Porto Alegre: Zouk, 2007.

CASTEL, Robert. Die Krise der Arbeit: Neue Unsicherheiten und die Zukunft des Individuums. Hamburg: Hamburger Edition HIS Verlag, 2011.

. Metamorfoses da questão social: uma crônica do salário. Petrópolis: Vozes, 1998.

CASTELLS, Manuel. The rise of the network society: the information age: economy, society and culture. v. 1. Oxford: Blackwell Publishers, 2010.

EDER, Klaus. A nova política de classes. São Paulo: Edusp, 2002.

GORZ, André. Misérias do presente, riqueza do possível. São Paulo: Annablume, 2004.

O imaterial: conhecimento, valor e capital. São Paulo: Editora Annablume, 2005.

LAHIRE, Bernard. A cultura dos indivíduos. Porto Alegre: Artmed, 2006.

MACIEL, Fabrício. A nova sociedade mundial do trabalho: para além de centro e periferia? São Paulo: Annablume, 2014.

MÜNCH, Richard. Globale Eliten, lokale Autoritäten. Frankfurt am Main: Suhrkamp, 2008.

NERI, Marcelo. A nova classe média: o lado brilhante da base da pirâmide. São Paulo: Saraiva, 2012.

OFFE, Claus. Capitalismo desorganizado. São Paulo: Brasiliense, 1994.

POCHMANN, Marcio. Nova classe média? $O$ trabalho na pirâmide social brasileira. São Paulo: Boitempo, 2012.

SENNETT, Richard. A corrosão do caráter: consequências pessoais do trabalho no novo capitalismo. Rio de Janeiro: Record, 2006.

. Die Kultur des neuen Kapitalismus. Berlin: Berliner Taschenbuch Verlags, 2007. 
SOUZA, Jessé. A construção social da subcidadania: por uma sociologia política da modernidade periférica. Belo Horizonte:UFMG; Rio de janeiro: Iuperj, 2003.

A ralé brasileira: quem é e como vive. Belo Horizonte: UFMG, 2009.

Os batalhadores brasileiros: nova classe média ou nova classe trabalhadora? Belo Horizonte: UFMG, 2010.

TAYLOR, Charles As fontes do self: a construção da identidade moderna. São Paulo: Edições Loyola, 1997.

UNGER, Roberto Mangabeira. O que a esquerda deve propor? Rio de Janeiro: Civilização Brasileira, 2008.

VESTER,Michael; ETT,All. Soziale Milieus in gesellschaftlichen Strukturwandel. Köln: Bund-Verlag, 1993.

WEBER, Max. A ética protestante e o espírito do capitalismo. São Paulo: Companhia das Letras, 2004.

Submetido em: 24/09/2016

Aceito em: 11/12/2016

\title{
END OFTHE SOCIAL CLASSES? THE CONTEMPORARY DEBATE IN EUROPE AND BRAZIL
}

\begin{abstract}
This article is divided into two parts: first, presents a synthesis of the discussion around the end of the social classes and their loss of analytical relevance in contemporary European debate. This is marked primarily by the historical context of the end of the Welfare-State. In the second part, it makes an analysis about the debate on the emergence of a new middle class in Brazil, which, for some authors, means a new working class. As a conclusion, it presents a brief analysis about the difference of treatment of the social classes theme in Europe and in contemporary Brazil, which reflects their respective empirical realities.
\end{abstract}

Keywords: Social classes. Welfare-State. Individualism. New middle class. New working class. 